\title{
DIE BE-TEKENING VAN KONSEPTE IN DIE OPVOEDKUNDE MET VERWYSING NA STAND- PUNTVERSKILLE AANGAANDE DIE SKOOL EN OUERHUIS AS GESAGSTRUKTURE
}

\author{
O.A. Henning \\ Departement Wysgerige Pedagogiek \\ Universiteit van die Oranje-Vrystaat \\ BLOEMFONTEIN
}

\begin{abstract}
Abstracl
In this article attention is focused upon the diversity of meanings that educationists attach to a societal relationship like the school. The opinion often appearing in literature on education that the school is an "extension" of the family and that the teacher can take action as a substitute parent is questioned in paricular. By means of a cosmological analysis of the societal stnuctures, school and family, an attempt is made to refute such statements. This variety of meanings which tend to cause confusion and are conveyed by the mentioned concepts in literature, is ascribed to the outcome of a diversity of paradignatic and theoretical presuppositions.
\end{abstract}

\section{INI.EIDING}

Die problematiek rondom teoretiese diversiteit in die Opvoedkunde wat as gevolg van uiteenlopende paradigmas en verskillende wyses van be-tekening van konsepte op standpuntverskille uitloop, kan 'n beginnerstudent of oningewyde leser van opvoedkundige literatuur verwar en selfs die status van die Opvoedkunde as vakwetenskap bevraagteken. Dit is egter so dat veel meer vakwetenskappe as die Opvoedkunde gebuk gaan onder teoretiese divergensies, wat veelal die indruk skep dat wetenskaplikes titeenlopend "uit baie monde" praat.

In hierdie artikel word beoog om die aandag toe te spits op die tipering van die skool as gesagstruktuur, in soverre die skool en huisgesin as twee samelewingsverbande met twee duidelik van mekaar te onderskeie individualiteitstrukture beskou behoort te word. Die kosmiese beginsel van soewereiniteit in eie kring vorm saam met die beginsel van universaliteit in eie kring die rasionaal vir die standpunt wat in hierdie artikel figureer. Volgens hierdie standpunt word die skool en huisgesin as opvoedingsvennote beskou, maar die een word nie as die plaasvervanger van die ander beskou nie. 


\section{DIVERGERENDE TIPERINGE VAN DIE SKOOL AS GESAGSTRUKTUUR}

\subsection{Die skool as "verlengstuk" van die ouerhuis}

Die skool word in die opvoedkundige literatuur op 'n hele paar maniere omskryf na aanleiding van die besondere taak, plek en perke daarvan in die samelewing. Opvoedkundiges wat in die tradisie van die reformatoriese denke teoreties rekenskap oor die presiese aard van die skool as gesagstruktuur probeer gee, het byvoorbeeld 'n probleem met die stelling wat veelal gangbaar is dat die skool' $n$ verlengstuk van die huisgesin is en dat die onderwyser as't ware plaasvervangende ouer is (vergelyk Landman, 1974:54; Van Loggerenberg \& Jooste, 1973:102).

Die vermaarde Suid-Afrikaanse opvoedkundige, W.A. Landman (1974:54-55) stel byvoorbeeld belangrike perspektiewe ten opsigte van die vennootskap wat tussen ouers en onderwysers in die wêreld van die opvoeding behoort te heers wanneer hy dit tereg in verband bring met die Doopbelofte wat sowel ouers as onderwysers onder die gelofte stel om te "onderrig" (ouers) en te "laat onderrig" (onderwysers). Met die bedoel-ing dat ouers en onderwysers hierin vennootskaplik baie nou moet saamwerk en dat ouers sekere opvoedingsaangeleenthede in die gedifferensieerde samelewing, waar ouers nie bevoegd is om sekere take te verrig nie, dit aan die onderwyser (skool) oorlaat, moet 'n mens uiteraard weens die vervlegting van verbande teen die agtergrond van die beginsel van universaliteit in eie kring akkoord gaan. Met die betekening van die be-doel-ing soos gestel, dat die onderwyser plaasvervangende ouer word as gevolg van die vennootskap, verskil opvoedkundiges egter, onder meer op kosmologiese gronde. Die wyse waarop die begrip onderwyser be-teken word, verskil onderling. Van Zyl (1975:324) stel dit eksplisiet: "As sekondêre opvoeder is hy (die onderwyser - O.A.H.) nie plaasvervangende ouer nie. Sy taak is aanvullend by die ouerlike taak". Hy help deur middel van formele onderwys en kennisverwerwing (vergelyk ook Snyman 1985:116-117; 122; 125; 129-130; 167).

\subsection{Struktuur-empiriese poging tot tipering}

Die probleem rondom 'n struktureel en aspektelik-noukeurige be-tekening van die skool en die posisie van die onderwyser binne daardie teoretiese individualiteitstruktuur, word op ' $n$ besondere wyse verhelder deur die kosmologiese aspekteleer waarvan die eksponente van die reformatoriese denkrigting hulle laat bedien. Die kosmologiese aspekte wat die Wysbegeerte van die Wetsidee stel, stel 'n mens teoreties en in beginsel in staat om, so wil dit voorkom, 'n totale werklikheidsgetroue beeld van die veeldimensionele geskape werklikheid deelagtig te word. Dit stel teoreties 'n logiesgeordende wetmatige kosmologiese totaalstruktuur voor. Hierdie totale struktuur toon 
of "bevat", teoreties klaarblyklik alle tot dusver bedinkbare, identifiseerbare synswyses (bestaanswyses), funksies, fasette, aspekte, modaliteite, sinmomente binne die kader waarvan stoflike entiteite, plante, diere en mense (die hele skepping) subjek- en objekfunksies kan hê en hulle self struktuurmatig openbaar. Die pluspunt van hierdie aspekteleer as besondere paradigma is dat dit teoreties poog om enersyds so ver moontlik nie mank te gaan aan 'n beperkende identifisering van werklikheidsaspekte nie, en andersyds poog om nie mank te gaan aan 'n reduksionistiese benadering waarby afsonderlik identifiseerbare aspekte na mekaar herlei of verabsoluteer word nie.

Die mens leef binne die godgeskape strukture van die empiriese werklikheid. Hierdie strukture is voorwetenskaplik gegee. Dit is nie die wetenskap wat die strukture daargestel het nie. Om wetenskap te beoefen, is maar 'n taak soos enige taak as reaksie op die mens se kultuuropdrag om te heers en te beheers. Die kenteoretiese ontdekking, identifisering en onderskeiding van bestaande kosmiese strukture wat langs logies-analitiese weg onderneem word, kom neer op die wetenskaplik-teoretiese beheersing van die empiriese werklikheid as gestruktureerdheid. Metodologies geskied dit dan onder meer en waarskynlik in mees volledige sin ten beste langs struktuur-empiriese weg en dit kan gesien word as die teoretiese kultuurtaak van die geesteswetenskaplike opvoedkundige wetenskapsbeoefenaar.

Die kosmiese of ontologiese struktuur wat deur middel van die aspekteleer voorgestel word, omsluit derhalwe ook kleiner strukture as spesifieke individualiteitstruktureelgetipeerde lewensvorme, soos onder andere skool, huisgesin, staat, kerk ensovoorts. Om die werklikheidsgetroue aard (al dan nie) van die Wysbegeerte van die Wetsidee met sy aspekteleer te kan verifieer, is dit sekerlik nodig om eers onbevooroordeeld 'n studie te maak van die besondere modaliteiteleer met sy vyftien wetskringe en sinkerne. As verwysingsraamwerk maak dit, in beginsel altans, die logiese objektivering van die werklikheid in totaliteit moontlik, segbaar en leesbaar en toon dit die eienskap om "plek te hê" vir alles wat ding of struktuur of skepsel en bestaanswyse van watter aard ook al is. Ook die individualiteitstrukture van die genoemde lewensvorme soos die skool en ouerhuis, kan teoreties in beginsel daarvan "afgelees" word en as't ware struktuur-empiries "ervaar" word, deur na die aspektelike funderings- en kwalifiserings- of bestemmingsfunksie daarvan te verwys.

Waarom die opvatting dat die skool 'n "verlengstuk van die ouerhuis" is en die onderwyser "plaasvervangende ouer" is, in beginsel bevraagteken kan word, kan dan juis van die andersheid van skool en ouerhuis (gesin) se individualiteitstrukture afgelees word (Schoeman, 1983:122-131). Die argumentasies en verduidelikings in dié verband, word egter eers helder en deursigtig indien hoorder of leser, soos gestel, bereid is om sonder vooroordeel tot diepgaande kennis te geraak van die aspekteleer as deel van die paradigma teen die agtergrond waarvan genoemde tiperinge van skool 
en onderwyser bevraagteken word. Eers wanneer 'n mens die fynere nuanses van 'n paradigma, trouens, van verskillende, selfs teenoormekaarstaande paradigmas, deelagtig geword het, kan dialoog gevoer word op 'n wyse waarop solidêr-krities minder by mekaar verby gepraat word en waarvolgens mekaar se kenteoretiese, ontologiese en antropologiese be-doel-ings billik en met insig verreken kan word.

Aan die hand van onderstaande diagram, wat deurentyd "geraadpleeg" behoort te word by die uiteensetting van die individualiteitstrukture, word gepoog om te motiveer waarom nie gesê behoort te word dat die skool die verlengstuk van die ouerhuis is en die onderwyser plaasvervangende ouer is nie.

\section{DIE HUISGESIN SE INDIVIDUALITEITSTRUKTUUR}

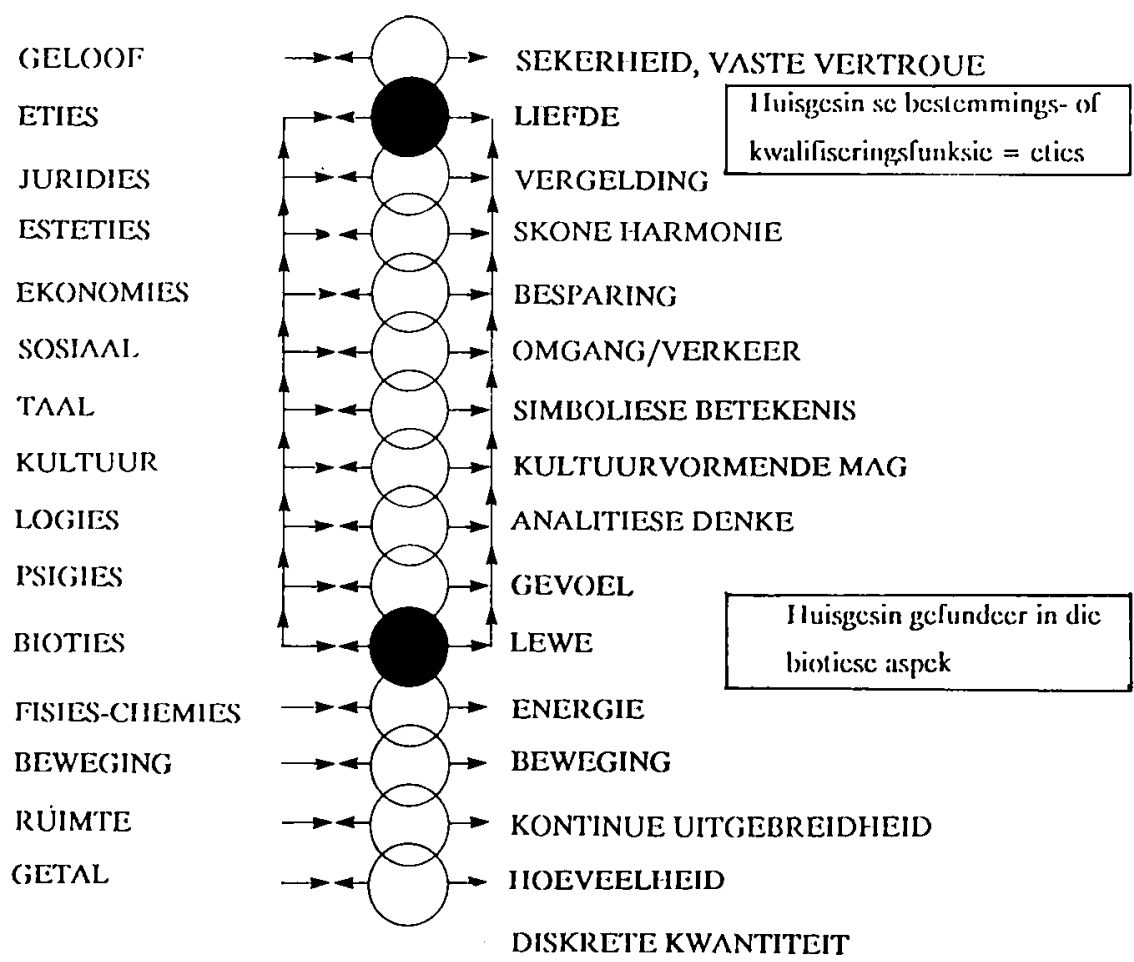




\section{DIE SKOOL SE INDIVIDUALITEITSTRUKTUUR}

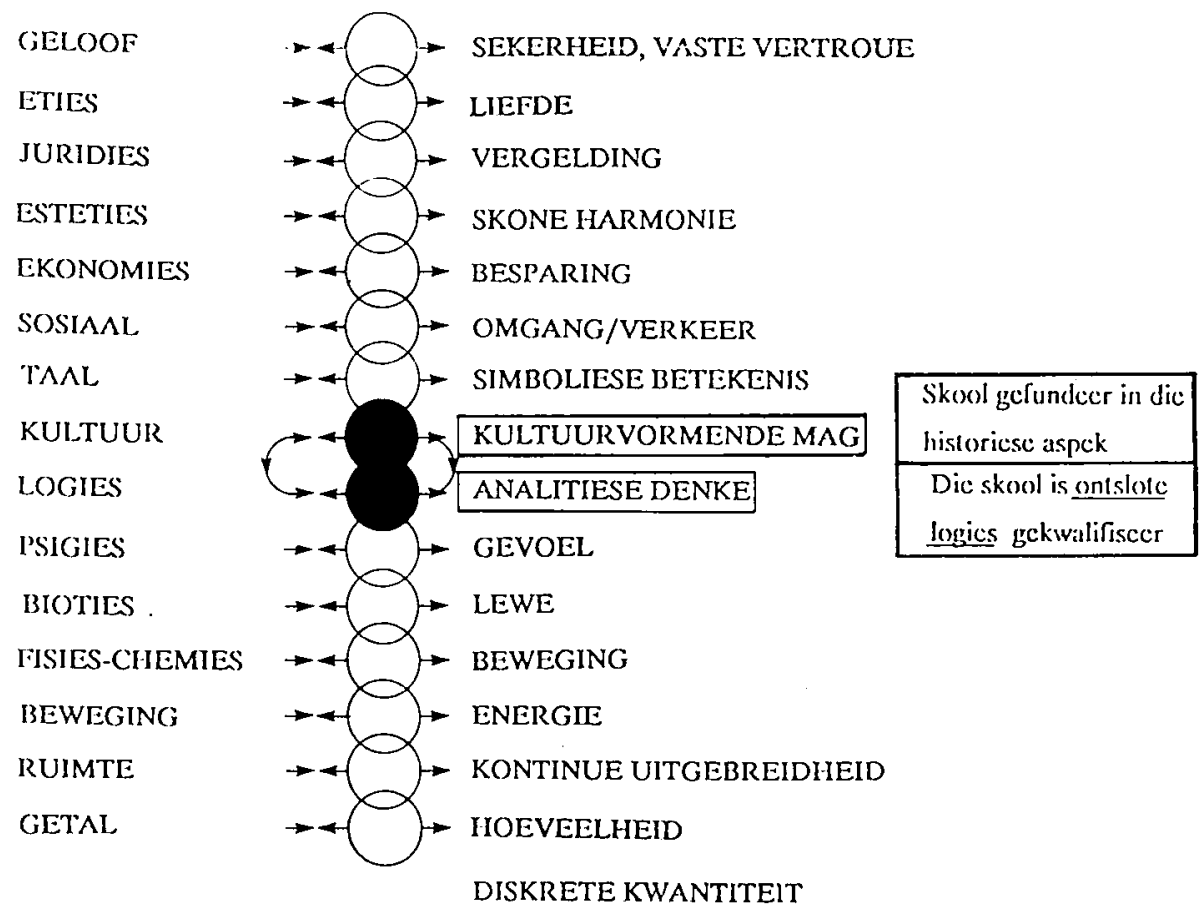

Êrens "binne-in" die totale aspektelike "bouwerk" (teoreties-sketsmatige strukturele voorstelling) van die aspektelike "voorkoms" van die totale werklikheid, is, soos gestel, ruimte vir die strukturele tipering as begripsmatige logiese objektivering van onder 
andere die lewensvorme skool en huisgesin as samelewingstrukture. Die wyse waarop die onderwyser se gesag en ampsbevoegdheid tot vergestalting kom is skool-tipies van aard en verskil van die vergestalting van ouerlike gesag in die eties-gekwalifiseerde gesinsverband. Daarom is die skool wesenlik nie huisgesin nie en die huisgesin wesenlik nie skool nie, ten spyte van hul gemeenskaplike, maar in elk geval ietwat anders "ge-aarde", of anders gestruktureerde belang by die opvoeding van die kind.

Die skool en die huisgesin besit elk 'n eie, tipiese individualiteit. Wend 'n mens nou bogenoemde "aspektebeeld of aspektegrafiek" as be-woord-ing van alle werklikheidsaspekte van die werklikheidstruktuur aan om die individualiteitstruktuur van die huisgesin daarvan "af te lees", dan sê ons die huisgesin is gefundeer in die biotiese aspek van lewe en word gekwalifiseer deur (vind sy bestemming in) die etiese aspek van liefde. Struktuurontledings word dus geformuleer deur die aanduiding van 'n aspektelike funderingsfunksie en 'n kwalifiserings- of bestemmingsfunksie binne die sfeer van die kosmiese aspekteverskeidenheid.

Die huisgesin is gefundeer in bloedverwantskap op grond van die lede daarvan se genetiese verbondenheid as gevolg van die biotiese lewewekking (kinders) wat basies dan van huis uit familieskap konstitueer (Dooyeweerd, 1969:266; Taljaard 1963:90, 91). 'n Gesin word egter as sodanig eers deur die liefdesband werklik as 'n egte, per definisie ideale gesin gekwalifiseer (Dooyeweerd, 1969:26; Strauss, 1978:273, 277; Venter, 1969:3; Spier, 1972:88; Schoeman, 1985:82). Diere en plante plant ook voort deur middel van biotiese prosesse, maar word nie eties saamgebind in huweliks- en gesinsverband nie. Die gesin is 'n normatiewe liefdesgemeenskap en is as sodanig gebaseer op daardie genoemde natuurlike bloedbande tussen die ouers en hulle kinders (Snyman, 1985:113). Hoe liefdevol en eties-korrek onderwysers ook al teenoor hul leerlinge optree, vul hulle nooit die plek van die ouer nie. Die onderwyser vervul sy normatiewe rol, waaronder ook sy etiese optrede val, altyd op onderwys-tipiese wyse en die ouer vervul sy rol op ouer- of gesinstipiese wyse. Hierdie uitspraak berus op struktuur-empiriese stande van sake rakende die twee onderhawige gesagstrukture (ouerhuis en skool). Die liefdesband wat die huisgesin (ouerhuis) as samelewingsverband kwalifiseer, dien volgens Dooyeweerd as 'n afskaduwing of analogie van die liefdesband tussen God en sy kinders, onbreekbaar gebind deur Christus se liefde (Dooyeweerd, 1969:269; Snyman, 1985:113). Die sketsmatige voorstelling van die aspekteleer van die Wysbegeerte van die Wetsidee stel 'n mens in staat om, soos van'n "werklikheidsgrafiek" af, die individualiteitstruktuur van die huisgesin af te lees as bioties gefundeer en eties gekwalifiseer (vergelyk diagramme).

Wat die skool betref, besef 'n mens dat dinge, plante en diere nooit tot skoolstigting sou oorgaan nie, omdat hulle nie soos die mens oor kultuurvormende mag beskik nie. (Let wel: kultuurvormende mag is die sinkern van die kultuurhistoriese aspek van die 
werklikheid - vergelyk die diagram met aspekte). Die skool is derhalwe as kultuurding in die kultuur-historiese aspek van die ontiese struktuur gefundeer. En watter aspek sou, fyn, basies en primêr beoordeel, dit wil sê in die laaste instansie, die skool as skool (wat niks anders as skool kan wees nie) kwalifiseer? 'n Mens kan laasgenoemde vraag klaarblyklik beantwoord as jy jouself eers afvra wat die primêre, taak (let wel, nie die breë, algemeen oorkoepelende veelaspektelike opvoedingstaak nie), van die skool is.

Die primêre of mees basiese taak van die skool slaan op die skepping van geleenthede vir die opvoedende (normduidende) ontsluiting en oordra van kennis (logies-analitiese aspek) en die ontwikkeling van vaardighede ten opsigte van alle lewenskaders. Trouens, allerlei vakke word onderrig en hierdie onderrigtaak is ' $n$ logies-analitiese aktiwiteit as spesifiek onderwysende opvoeding. Dit maak nie saak of dit gaan om syfervakke binne die sfeer van die getalsaspek van die werklikheidstruktuur, Fisika of Chemie binne die sfeer van die fisies-chemiese aspek, Biologie as vakwetenskap binne die kader van die biotiese aspek, Geskiedenis binne die kader van die kultuurhistoriese aspek, Taalkunde binne die "domein" van die linguale teken-aspek, Ekonomie binne die sfeer van die ekonomiese aspek, Godsdiensonderrig of Bybelkunde binne die konteks van die geloofsaspek nie, onderwys bly by die ontsluiting van ál bogenoemde soorte kennis basies en tipies ' $n$ logies-analitiese saak. Derhalwe kan die skool as struktuur logies-taalmatig be-teken (getipeer) word as kultuur-histories gefundeer en ontslote logies gekwalifiseer (vergelyk diagram).

In die lig van bogenoemde word elke vakonderwyser se korttermyn-doelstelling, sy nabygeleë "bestemming" gesien as die skepping van geleenthede vir die opvoedende logies-analitiese ontsluiting van besondere vakwetenskaplike kennis. Kennis wat ouers informeel in gesinsverband meedeel, is nie vakwetenskaplik georiënteer nie. Die primère taak van die skool kan dan nou be-teken of getipeer word as die normatiewe. ekspansiewe verruiming en verdieping van die logies-analitiese aspek van die opvoedeling. Dit beteken dat die logiese aspek hom laat geld en speel 'n intellektualiserende rol in alle vakke wat deur alle ander aspekte (as die logiese) in die ry van werklikheidsaspekte gekenmerk word. Die logiesc word as't ware uitgebrei (vergelyk "ekspansief") na vakwetenskappe van allerlei aspektelike aard: histories, ekonomies, sosiaal, die getalsaspek ensovoorts, al na gelang van die modale aard van die besondere vakwetenskap.

Dit is dan nou die logies-analitiese aard en die geïntellektualiseerde kwaliteit van die onderwysende opvoedingstaak wat meebring dat die kwalifiserings- of bestemmingsfunksie van die skool primêr in die ontslote logies-analitiese aspek van die kosmiese werklikheid gesoek moet word, al sou gesê kon word dat die skool benewens die logiesanalitiese onderrigtaak, ook sy opvoedingsfunksies daarmee integreer as opvoedingsfunksies in sosiale, etiese en alle ander aspektelike verbande. 


\subsection{Soewereiniteit in eic kring en universaliteit in eie kring}

Die struktuurontleding van die skool, naamlik dat hy kultuur-histories gefundeer en ontslote logies gekwalifiseer is, impliseer kosmologies beskou, dat die skool tog nie die verlengstuk van 'n struktuur kan wees, wat as iets anders, synde bioties gefundeer en eties gekwalifiseer ' $n$ unieke, aardeie soewereiniteit in eie kring vertoon en huisgesin heet nie. Huisgesin en skool bestaan naas mekaar as verskillende samelewingstrukture met onder andere gemeenskaplike belange, naamlik die bevordering van die heil van die kind. As vennote of belangegroepe hanteer die skool en huisgesin die opvoedingstaak egter langs verskillende (skool-tipiese en gesins-tipiese) weë en op verskillende wyses, die een nie as die verlengde van die ander, of as verlengstukke van mekaar nie, maar as die relatief-selfstandige vennoot in die wêreld van die opvoeding, op grond van die beginsel van vervlegting van verbande en universaliteit in eie kring.

Uit bogenoemde volg nou dat die identiteit van die huisgesin enersyds en van die skool andersyds, elk as konkreet funksionerende lewensvorm of samelewingstruktuur, met as gemeenskaplike belang die heil van die kind, gesien word in die lig van die normerende struktuurbeginsel van ouerhuis-wees en skool-wees. 'n Wetenskaplik-verantwoorde artikulering van die strukturele tipisiteit van die huisgesin en skool as twee verskillende lewensvorme, behoort in beginsel te verhoed dat die een goedskiks reduksionisties as die verlengstuk of plaasvervanger van die ander beskou en be-teken word. Die op die onderwysende opvoedingsgerigte verbandstempel (kwalifisering) van die skool bepaal die unieke skool-geaarde wyse waarop die skool in alle aspekte van die werklikheid funksioneer. Dieselfde geld ook, onder die beginsel van soewereiniteit in eie kring, vir die gesin, met betrekking tot die gesin-tipiese wyse van funksionering in alle aspekte van die werklikheid.

Die erkenning van die ontslote logiese verbandsaard van die skool as opvoedinginstansie impliseer inherente struktuurgrense (bevoegdheidsgrense) vir die onderwysende opvoedingsoptrede van die onderwyser, wat hom nie maar summier die ouer kan laat vervang nie. Juis die grondleggende struktuurbeginsel bied 'n kriterium wat 'n mens in staat stel om tipiese skool- of onderwysdoelstellinge van nie-tipiese (buiteskoolse) doẹlstellinge soos dié van die ouerhuis, te onderskei. Tóg kan die huisgesin nooit los van die skool bestaan nie, net soos hy ook nie los van die staat, kerk en so meer kan bestaan nie. Die enkapsis beteken egter nooit 'n opgaan van die een samelewingsverband in 'n ander een nie. Dit beteken 'n vervlegting van individualiteitstrukture waarin elke verband sy eie selfstandigheid behou (vergelyk Spier, 1972:105111; Snyman, 1985:167). Die beginsels van soewereiniteit in eie kring en universaliteit in eie kring geld deurgaans parallel en hef mekaar nooit op nie.

Verdere besinning oor die voorgenoemde struktuurbeginselgedagte bring aan die lig 
dat elke selfstandige lewensvorm (soos huisgesin en skool), in 'n gedifferensieerde samelewing sy eie organisasievorm besit. Hierdie eie-geaarde organisasievorm hang saam met die feit dat elke sodanige lewensvorm oor'n eie en eenduidig-gedifferensieerde kwalifiseringsfunksie beskik, wat aan die spesifieke lewensvorm 'n tipiese spesifikasie verleen. Dit juis, maak dit derhalwe deursigtig dat die een lewensvorm nie die ewebeeld, verlengde of plaasvervanger van die ander kan wees nie (vergelyk Strauss, 1989:106; 120).

Daar moet ook daarop gelet word dat daar 'n merkbaar onderskeie wyse van omgang en verkeer tussen ouers as gesagsfigure en kinders as gesagsonderhoriges in gesinsverband enersyds, en onderwysers en leerlinge in skoolverband andersyds is. Om huisgesin en skool as verlengstukke van mekaar te tipeer en onderwysers voor te hou as plaasvervangende ouers, is om onkrities en lukraak te onderskei tussen verbande en om hulle ontologies verkeerd te identifiseer. 'n Nadere, spesifiek wetenskaplike (respektiewelik abstraherende) aanduiding van die spesifieke verskille tussen samelewingsverbande, behoort skrywers en sprekers te dissiplineer om struktureel korrek met entiteite en strukture in die skepping om te gaan, ook in die talige betekening van die besondere konsepte soos byvoorbeeld huisgesin en skool. Die argument dat hierdie aanspraak op hareklowery en as't ware op much ado about nothing neerkom, hou nie steek nie, veral in die lig van die wetenskaplike vereiste ten opsigte van korrekte kosmologiese verrekening van strukture, korrekte be-tekening van konsepte en vermyding van reduksionismes en verabsoluterings.

Struktuurmatig beskik ouerhuis, skool, soos ook staat, kerk en so meer as samelewingsverbande, gesagstrukture of belangegroepe, elk oor wat Strauss, (1989:121) 'n "begrensde territorium" noem (vergelyk die beginsel van soewereiniteit in eie kring). Elke lewensvorm (soos gesin en skool) gaan op tipiese, aard-eie wyse oor tot die organisering van menslike subjekfunksies en doen dit deurgaans onder leiding van 'n radikaal-tipiese kwalifiseringsfunksie (Strauss, 1989:120).

\subsection{Dic individuecl-tipiese eie-aard van verbande}

Ten spyte van bogenoemde struktuur-empiriese stand van sake vind 'n mens in die opvoedkundige literatuur dat sommige skrywers goedskiks daarmee volstaan dat die skool die verlengstuk van die ouerhuis is en dat die onderwyser plaasvervangende ouer is. Skool, ouerhuis, onderwyser en ouer word dan as sodanig in bogenoemde terme beteken, terwyl opvoedkundige eksponente van die Wysbegeerte van die Wetsidee, in Schoeman (1974:13) se woorde dit só stel: 
Wanneer gelet word op die individualiteitstrukturcle verskille tussen huisgesin en skool, dan word dit duidelik dat hoewel albei direk by die opvoedende onderwys van die kind betrokke is, hulle onderlinge bemocienisse met die opvoedeling vanweë stniktutr-verskille (my kursivering -

O.A.H.) nie met mekaar geïdentifiseer mag word nic.

Tóg bly ouerhuis en skool strykdeur opvoedingsvennote wat ten opsigte van kinderopvoeding op bepaalde terreine medeseggenskap mag opeis. Elk van hierdie samelewingstrukture het immers ten opsigte van dieselfde kinders sy bepaalde opvoedingstaak. Hierdie eiesoortige, gedifferensieerde belange van ouerhuis en skool by die opvoeding van kinders is op 'n besondere wyse geïntegreer. Ten opsigte van die onderwysende opvoeding by die skool het die ouer, vanweë sy eerste reg op die belange van sy kind, wel die reg en verantwoordelikheid om onderwysersoptrede langs die regte kanale te bevraagteken indien etiese en ander norme nie nagevolg word by die ontsluiting van die logies-analitiese funksie van die kind nie. Ten spyte van die noue belangevervlegting, moet die beginsel steeds verreken word dat opvoedingskompetensie (-mag), in die geval van die huisgesin ontstaan as gevolg van familiebande wat die lede van die gesin onderling aan mekaar bind, terwyl die skool se bevoegdheid ontstaan as gevolg van professionele opleiding en meerdere kennis van vakspesialiste wat ook opvoeder-onderwysers is. So beskik die onderwyser weens sy besondere bevoegdheid en takt oor onderwys-tipiese gesag binne die tipiese individualiteitstruktuur van die skool en die ouer oor ouer- of gesinstipiese gesag binne die tipiese individualiteitstruktuur van die huisgesin as belangegroep, elkeen relatief soewerein in eie kring.

\section{SIOTPERSPEKTIEF}

Dit is duidelik dat die fundering en tipering van agogiese belangegroepe (ouers en onderwyserskorps) wat aktief opvoedend optree, kosmologies te bepaal is aan die hand van elk se besondere individualiteitstruktuur. Aan die hand van die relevante struktuurontledings kom 'n mens by implikasie uit by die anders-geaarde vorm van opvoedende leidinggewing en gedifferensieerde opvoedingsdoel of -bestemming van huisgesin en skool. Aan die hand van skrywers soos Schoeman (1987:426-427) en Venter (1969:20-21) word daarmee akkoord gegaan dat verskillende samelewingsvorme se eiesoortige karakter en opvoedingstaak in ooreenstemming is met die kosmiese beginsels van soewereiniteit in eie kring en universaliteit in eie kring. Dit word derhalwe aanvaar dat daar essensiële en aanwysbare verskille is tussen byvoorbeeld die vorming van die ontslote logiese opvoedingsmag van die skool waar wetenskap beoefen word en die huisgesin se etiese kwalifiseringsfunksie wat sy opvoedingstaak tipeer. So word albei ook as wesenlik anders getipeer as byvoorbeeld die kerk as geloofsverband wat belang het by die vorming van godsdienstige geloofsmag by die kinders. Inderdaad, op grond van die eiesoortige karakter van elke afsonderlike same- 
lewingstruktuur wat belang het by kinderopvoeding, is die skool nie die verlengstuk van die ouerhuis nie en is onderwysers nie plaasvervangende ouers nie. Hulle is hoogstens opvoedingsvennote, elk met aard-eie opvoedingsbevoegdhede op unieke, eie terreine.

\section{BIBLIOGRAFIE}

DOOYEWEERD, H. 1969. A ncw critique of theorctical thought. III \& IV. Translated by Frecman, David H. \& De Jongste, H. Philadelphia : The Presbyterian Reformed Publishing Co.

LANDMAN, W.A. 1974. Leesbock vir die Christen-opvoeder. Pretoria : N.G. Kerkbockhandel.

SCHOEMAN, P.G. 1974. Ouerseggenskap - Fundering en omlyning. Die Skoolblad, Februarie. Blocmfontcin : OVSOV

SCHOEMAN, P.G. 1983. Wysgerige Pedagogick. Pretoria : Sacum Beperk.

SCHOEMAN, P.G. 1985. Historical and Fundamental Education. Pretoria : De Jager-HAUM Publishers.

SCHOEMAN, P.G. 1987. Metavrae van 'n agologiese vakfilosofie - verkenning van enkele transendentc en transendentale aprioricë. Bloemfontein. (Ongepubliseerde procfskrif (D. Phil.) - UOVS.)

SNYMAN, P.J. 1985. Die bepalers van dic gees en rigting van die opvoedende skoolonderwys. Potchefstroom. (Ongepublisecrde proefskrif (D. Ed.) - PU vir CHO.)

SPIER, J.M. 1972. Oriëntering in die Christelike Wysbegeerte. Bloemfontein : Sacum Beperk.

STRAUSS, D.F.M. 1978. Inleiding tot die kosmologie. Bloemfontein : Sacum Beperk.

STRAUSS, D.F.M. 1989. Dic mens en sy wêreld. Bloemfontein : Tekskor BK.

TALJAARD, J.A.L. 1963. Kursus in lewens- en wêteldheskouingsleer en menslike samelewingsverbande. Potchefstroom : Pro Rege.

VAN LOGGGERENBERG, N.T. \& JOOSTE, A.J.C. 1973. Verantwoordelike opvoeding. Blocmfontein : Nasionale Bockhandel.

VAN ZYL, P. 1975. Opvoedkunde. Deel I. Tweede Druk. Johanneshurg : Bockhandel De Jong (Edms) Bpk.

VENTER, E.A. 1969. Dic gelowige in dic samelewing. Bloemfontein : Sacum Beperk. 
